\title{
MicroRNAs as efficient biomarkers in high-grade gliomas
}

\author{
Anna-Maria Barciszewska ${ }^{1,2}$ \\ ${ }^{1}$ Intraoperative Imaging Unit, Chair and Clinic of Neurosurgery and Neurotraumatology, Karol Marcinkowski University of Medical \\ Sciences, Poznan, ${ }^{2}$ Department of Neurosurgery and Neurotraumatology, Heliodor Swiecicki Clinical Hospital, Poznan, Poland
}

\begin{abstract}
High-grade gliomas are the most aggressive and devastating brain neoplasms. Therefore much effort is put on understanding their background as well as development of new effective diagnostic and therapeutic methods. However, until now the genetic only approach has not provided a satisfactory answer. Recently, it has been shown that the epigenetic issue is important for high-grade gliomas' development and progression. Out of many epigenetic mechanisms, as DNA methylation, histone methylation and acetylation, especially microRNAs showed to be deeply involved in the carcinogenesis process.

MicroRNAs are short non-coding RNAs. They are new candidates for human disease biomarkers due to their simple identification. MicroRNAs are stable in tissue and body fluids, what makes them very prospective non-invasive, blood-based biomarkers. There is a lot of data showing that various profiles of serum microRNAs are linked to numerous neoplastic processes, indicating that microRNAs can be really a new class of biomarkers for human diseases.
\end{abstract}

Key words: microRNA, miRNA, miR, biomarker, high-grade glioma, HGG, glioblastoma, GBM.

\section{Introduction}

Histopathology of tumour specimens gained by microsurgical resection or stereotactic biopsy is a standard diagnostic procedure for patients with high-grade gliomas (HGG). The neuropathological system classifies gliomas according to their morphological resemblance to the corresponding glial cells, cytoarchitecture and immunohistological properties [37]. However, the clinical course of the tumours comprising the same histopathological entity varies significantly. Magnetic resonance imaging is current- ly the best instrumental method for staging of the disease and follow up, but it reveals tumours only at a macroscopic level. It is clear that the effective management of any malignant neoplasm, and brain tumour particularly, requires a diagnosis at an earlier stage, and that states the need for specific and sensitive biomarkers. Although many potentially useful probes have already been suggested, no such markers have been established for brain tumours. In this review several specific microRNA biomarkers will be presented and discussed, including those identified by our group [47]. 


\section{Brain gliomas}

Human brain cancers form a family of approximately 120 heterogeneous tumour entities and variants [37]. Their annual incidence accounts for $1.8 \%$ of all new cancer cases and the mortality reaches $2.3 \%$ of cancer deaths worldwide [26]. Gliomas account for over $70 \%$ of all primary brain tumours in adults, and they are divided into astrocytic, oligodendroglial, mixed, ependymal and embryonal types [37]. The astrocytic type occurs mainly in adults, including the most common (65\%) and most malignant type - glioblastoma (GBM). That typically infiltrates into the adjacent cortex and through the corpus callosum into the contralateral hemisphere making itself surgically untreatable. From a histopathological point of view gliomas are classified by the cell of origin and grade. Grades I to IV are based on histology and clinical criteria [37]. Grade I is assigned to tumours with low proliferative potential, grade II covers diffusely infiltrative tumours with cytological atypia, grade III shows anaplasia and mitotic activity and in grade IV tumours additionally microvascular proliferation and/ or necrosis is seen.

Malignant gliomas (HGGs, grade III and IV) are the most common type of primary brain tumours. Each year in more than 22,000 people in the United States a malignant glioma is detected [63], and most of that group will die within the first two years from diagnosis despite aggressive chemo- and radiotherapy. However, many of these relatively uniformly treated patients advance more quickly than others to recurrence and death. It is very rare for GBM patients to survive longer than 3 years [9]. Better prognosis is associated with several clinical and histopathological features, including young age, good performance status, gross total resection, adjuvant treatments, giant-cell subtype and oligodendroglial differentiation [25,37,56]. Glioblastoma patients differ in the clinical presentation and response to treatment because of a strong inter-tumoural heterogeneity coming from different gene mutations affecting signalling networks. Several molecular GBM subtypes have been identified [5]. The proneural subtype localizes typically in the frontal cortex, usually has IDH1/IDH2 and TP53 mutations, and demonstrates better prognosis and sensitivity to Notch inhibition [46] than the mesenchymal subtype, which is more aggressive, with greater vascularity, displaying more NF1 lesions, and depending on TGF- $\beta$ and NF- $\mathrm{kB}$ activity. The classical subtype is aggressive and frequently has EGFR lesions [46]. A fourth subtype, neural glioblastoma, is less well characterized.

The neuro-oncological practice depends strictly on tumour classification. Therefore therapies are applied in a relatively uniform way to all patients with a given histopathological diagnosis. Furthermore, classification constrains the scientific approach to brain neoplasia studies, with biological understanding based on presumptions about specific tumour types [24]. However, it is known that histologically identical tumours may have a very different outcome and response to treatment. Therefore cancer heterogeneity, both on a genetic and epigenetic level, has implications for therapy and shows challenges for the rational design of effective treatment rules [43]. Molecular markers with both diagnostic and prognostic potential contribute valuable tools by redefining tumour subtypes within each grade.

\section{Biomarkers}

A biomarker is a chemical compound specifically relevant to the disease, which can be applied to monitor the current neoplasm's state. The marker, despite having high diagnostic and prognostic values, may also suggest targeted therapies. Selective biomarkers can identify susceptibility risks and would be critical for establishing a proper time point for effective treatment. It is obvious that patients with early detected tumours have better chances for recovery and survival than those with advanced neoplasms at the time of diagnosis.

Molecular markers are changing the traditional classification by redefining tumour subtypes within each grade of malignancy and providing diagnostic and prognostic information. They become more and more an integral part of neurooncological practice. Biomarker status is already critical for clinical decisions in some gliomas' subtypes. For example, IDH1/2 mutations show favourable prognosis across all glioma grades [58,62]. Chromosomal co-deletion of $1 p / 19 q$ is positively predictive for chemotherapeutic response in anaplastic oligodendrogliomas [57]. O6-methylguanine-DNA methyltransferase (MGMT) promoter hypermethylation is a favourable prognostic marker in astrocytic high-grade gliomas [48]. It is also predictive for chemotherapeutic response in anaplastic gliomas and GBM $[22,27,56]$. 


\section{MicroRNAs}

MicroRNAs (miRNAs, miRs) form a family of small non-coding RNA molecules of 18-25 nucleotides that function in post-transcriptional gene regulation $[54,55]$. To date there have been ca. 2000 different human miRNAs referenced in the miRBase (release 21; June 2014). They are involved in a number of biological processes including cell proliferation, differentiation, developmental timing control, apoptosis and stress responses, as well as pathological states such as cancer [15,23].

miRNAs regulate gene expression through both translational repression and degradation of target messenger RNAs (mRNAs). The biogenesis of miRNAs involves two processes. The first one occurs in the nucleus, where the primary transcript (pri-miRNA) is processed into a precursor (pre-miRNA) by a nuclear RNase III (DROSHA). The second event takes place in the cytoplasm. The pre-miRNA is exported by exportin $V$ from the nucleus and is cleaved by Dicer into a short-lived dsRNA of about 20-25 nucleotides. Then the double-strand is unwound and one strand forms the mature miRNA, which is incorporated into an Argonaut (Ago)-protein containing complex called the RNA induced silencing complex (RISC). The mature miRNA within the RISC recognises complementary sites in the 3'-UTR of target genes, what results in translational inhibition or destabilisation of the target mRNAs and downregulation of the encoded protein expression [19].

It is estimated that up to $50 \%$ of all human protein-coding genes are regulated by miRNAs. Each miRNA regulates up to hundreds of different mRNAs, and each mRNA is regulated by tents of miRNAs [55]. Their expression is population-, race-, and gender-dependent, as well as related to tissue state (healthy or diseased), and disease subtype [55]. MiRNAs are considered to be fundamental to normal cellular function in eukaryotes, and the alteration of microRNA expression and activity has been implicated in a variety of pathological processes. The greatest challenge for molecular medicine is while miRNAs regulate many mRNAs, they impact many proteins.

MiRNAs can be considered as cancer biomarkers when variations in their expression identify the cancerous state. Until now almost all analysed tumours have shown distinct miRNA profiles compared to normal tissues [38]. These profiles can be further associated with prognostic factors and disease progression $[6,66]$.

\section{MicroRNAs as biomarkers of gliomas}

It has been shown that miRNAs are integrally involved in brain gliomas' development and progression $[1,12]$. They are essential regulators of many key pathways implicated in tumour pathogenesis $[10,18]$. Because miRNAs have been shown to play crucial roles in glioblastoma progression, invasion, tumour growth, and therapy responses, it is very likely that some miRNAs could be useful biomarkers in brain tumour patients.

MiRNAs expression can be altered in brain tumour through a variety of mechanisms including chromosomal changes, epigenetic defects and mutations in the machinery of their biogenesis $[21,36]$. There are many data showing that miRNA signatures can refine glioblastoma classification, differentiate GBM subclasses, as well as provide regulatory links to disrupted signalling pathways such as those facilitating cell growth [29]. Some studies show lower miRNA expression in tumour samples, what can be a function of cellular differentiation status [38]. Microarray studies of glioma tissue have implicated a number of miRNAs involved in glioma formation and propagation [47]. However, a comprehensive set of these differentially expressed RNA species has not been produced. Our group, based on miRNA microarray data analysis and deep RNA sequencing of miRNAs in normal human brain and tumour tissue, has recently found several RNA signatures, which were complemented with meta-analysis [47].

First we selected miRNAs that were most frequently deregulated in glioblastoma tissues as well as in peritumoral areas and compared with normal human brain. There were 22 differentially expressed miRNAs when comparing normal brain and brain tumour adjacent tissue [47]. The analysis revealed 6 miRNAs with elevated expression and 16 miRNAs with low expression within the tumour borders. 21 miRNAs found in the borders of gliomas were also identified in GBM. miR-625 was present within the border tissue, but not in GBM. Five overexpressed miRNAs, including the most abundant miR-21, are involved in the increased invasion and migration, but 15 were downregulated (Table I). We identified miRNAs associated with the progression from glioma grade III to grade IV. They are generally upregu- 
Table I. Human microRNAs as high-grade glioma drivers, differentially expressed compared to adjacent tissue $[7,47]$

\begin{tabular}{|cccc|}
\hline No. & Overexpressed & No. & Underexpressed \\
\hline 1. & 21 & 1. & 7 \\
\hline 2. & $142-5 p$ & 2. & 124 \\
\hline 3. & 155 & 3. & 128 \\
\hline 4. & $221 / 222$ & 4. & $129^{*}$ \\
\hline 5. & $542-5 p$ & 5. & $129-3 p$ \\
\hline 6. & 630 & 6. & 132 \\
\hline 7. & 1260 & 7. & 136 \\
\hline & & 8. & 137 \\
\cline { 2 - 4 } & & 9. & $139-5 p$ \\
\cline { 2 - 4 } & & 10. & 153 \\
\cline { 2 - 4 } & & 11. & $323-3 p$ \\
\cline { 2 - 4 } & & 12. & $330-3 p$ \\
\cline { 2 - 4 } & & 13. & 410 \\
\cline { 3 - 4 } & & 14. & 598 \\
\hline & & 16. & 625 \\
\hline
\end{tabular}

Table III. Differentially expressed human microRNAs in glioblastoma versus normal brain $[7,47]$

\begin{tabular}{|c|c|c|c|}
\hline No. & Overexpressed & No. & Underexpressed \\
\hline 1. & $9-5 p$ & 1. & $7-5 p$ \\
\hline 2. & $10 a-5 p$ & 2. & $124-3 p$ \\
\hline 3. & $10 b-5 p$ & 3. & $128-3 p$ \\
\hline 4. & $15 b-5 p$ & 4. & $129-5 p$ \\
\hline 5. & $16-5 p$ & 5. & $132-3 p$ \\
\hline 6. & $17-5 p$ & 6. & $136-5 p$ \\
\hline 7. & $20 a-5 p$ & 7. & 137 \\
\hline 8. & $21-5 p$ & 8. & $138-5 p$ \\
\hline 9. & $25-3 p$ & 9. & $139-5 p$ \\
\hline 10. & $92 a-3 p$ & 10. & $153-3 p$ \\
\hline 11. & $92 b-3 p$ & 11. & $154-3 p$ \\
\hline 12. & $93-5 p$ & 12. & $203 a$ \\
\hline 13. & $106 a-5 p$ & 13. & $218-5 p$ \\
\hline 14. & $106 b-5 p$ & 14. & $323 a-3 p$ \\
\hline 15. & $130 a-3 p$ & 15. & $328-3 p$ \\
\hline 16. & $130 b-3 p$ & & \\
\hline 17. & $155-5 p$ & & \\
\hline 18. & $182-5 p$ & & \\
\hline 19. & $196-5 p$ & & \\
\hline 20. & 210 & & \\
\hline 21. & $221 / 222$ & & \\
\hline
\end{tabular}

lated (Table II). The most interesting is the panel of 35 differentially expressed miRNAs in glioblastoma versus normal human brain (Table III). There are 20
Table II. Potential new microRNA markers for gliomas' progression from grade III to IV $[7,47]$

\begin{tabular}{|c|c|c|c|}
\hline No. & Overexpressed & No. & Underexpressed \\
\hline 1. & $20 a-3 p$ & 1. & $33 a$ \\
\hline 2. & 134 & 2. & 197 \\
\hline 3. & $144^{*}$ & 3. & $340^{*}$ \\
\hline 4. & $150^{*}$ & 4. & 381 \\
\hline 5. & 202 & 5. & $574-3 p$ \\
\hline 6. & $221 / 222$ & & \\
\hline 7. & $301 b$ & & \\
\hline 8. & 378 & & \\
\hline 9. & $483-5 p$ & & \\
\hline 10. & 494 & & \\
\hline 11. & $500^{*}$ & & \\
\hline 12. & $502-3 p$ & & \\
\hline 13. & $513 a-5 p$ & & \\
\hline 14. & 575 & & \\
\hline 15. & 939 & & \\
\hline 16. & 940 & & \\
\hline 17. & 1202 & & \\
\hline 18. & $1207-5 p$ & & \\
\hline 19. & $1224-5 p$ & & \\
\hline 20. & $1225-5 p$ & & \\
\hline 21. & 1246 & & \\
\hline 22. & 1260 & & \\
\hline 23. & 1275 & & \\
\hline 24. & 1290 & & \\
\hline 25. & 1471 & & \\
\hline 26. & 1915 & & \\
\hline
\end{tabular}

and 15 miRNAs up- and downregulated, respectively. One can see the highly expressed miRNA-9, as well as miRNA-21 and 155, what is shown in Table I. They can be used as novel biomarkers and potential therapeutic targets for GBM. MiRNA-7, 124, 128, 129, 132, 136, 137, 139, 153 and 323 overlap with those downregulated listed in Table I. Differentially expressed miRNAs in brain tumour and adjacent tissue reflect the crosstalk between cancer cells and their local environment, which is a key feature of establishing and maintaining a malignant state. Future validation studies of these miRNAs, in combination with other brain tumour biomarkers hold a promise for clinical practice.

\section{Candidate microRNAs for high-grade gliomas biomarkers}

Regarding the up-to-date literature findings and our laboratory results we can characterize the most 
promising of miRNA to be effective biomarkers for high-grade gliomas, especially GBM.

microRNA-21 shows overexpression in GBM and other gliomas in a grade-specific manner $[4,7$, $31,34,41,59]$. It affects the major cancer pathways: TGF- $\beta$, p53, and mitochondrial initiated apoptosis pathways. The miR-21 knock down in glioma cell lines leads to upregulation of tumour suppressor proteins including p53, Bax, DAXX, APAF1, p21, TAp63 and TGFBR2 [45]. Other studies showed that miR-21 regulates matrix metalloproteinase inhibitors (RECK and TIMP3) therefore implicates tissue invasion [13].

microRNA-10b seems to be deeply involved in glioblastoma progression because its expression levels clearly correlate with tumour grade [50]. It is overexpressed in GBM $[50,65]$ and enhances GBM invasiveness [50].

microRNA-221/222 were upregulated in gliomas and cell lines, but in HGGs with increased proliferation rates miRNA-221 levels were distinctly higher [7]. The direct link was found between miRNA-221/222 and cell cycle progression [42]. The ability of miRNA$221 / 222$ to negatively regulate the pro-apoptotic gene PUMA is responsible for its anti-apoptotic effect [69]. The overexpression of PUMA changes the phenotypes caused by the overexpression of microRNA-221/222 $[42,69]$, what suggests that miR-221/222 enhances the proliferative potential of tumour cells. The other way of miRNA-221 action in changing apoptotic signalling and altering cell cycle leads through BIRC family of neural cell fate regulators. It was shown that miRNA-221 is selectively upregulated in glioma tissue samples and cell lines, whereas its target, encoding the survivin-1 homolog BIRC1, a neuronal inhibitor of apoptosis protein (NIAP), is downregulated [40].

microRNA-17 92 cluster is upregulated in glioblastoma cell lines and tumour samples and is composed of miRNA-17-3p, -17-5p, -18a, -19a, -19b, -20a, and -92a [41]. The cluster targets are tumorigenic regulators of DNA-repair and angiogenesis (CTGF, and POLD2), and anti-proliferative transcripts (TGFBRII, SMAD4, and CAMTA1) [11,41].

Compared to non-neoplastic brain tissue microRNA-451 is overexpressed in glioma cells [14,44] and regulates the adaptive response in metabolic stress and low glucose availability [16].

The other upregulated microRNA in highly aggressive GBM cell lines is microRNA-145 [30]. That fact promotes decreased proliferation and invasion of
GBM cell lines [33]. Oct4 and Sox2 are proved to be targets of miR-145 mediating the loss of "stemness".

One of the most commonly downregulated microRNAs in glioblastoma [17] and glioma cell lines, when compared to age-matched controls, is microRNA-128 $[4,34]$. The downregulation of miRNA-128 inversely correlates with the WHO tumour grade. While miRNA-128 is downregulated in grade II-IV tumours, the levels in HGGs are significantly lower [69]. When overexpressed, miRNA-128 decreases the proliferative potential of glioblastoma cell lines in vitro and in GBM xenografts. miR-128 is also proposed to act by deregulation of self-renewal in glioma stem cells [17]. MiR-128 downregulation promotes an undifferentiated glioma phenotype via increased expression of its targets: angiopoietin-related growth factor protein 5 (ARP5, ANGPTL6), a transcription suppressor promoting stem cell renewal and inhibiting tumour suppressor genes expression involved in senescence and differentiation, Bmi-1, and a transcription factor critical for the control of cell-cycle progression, E2F-3a [8]. Addition of exogenous miRNA-128 to GBM cell lines restored the correct expression of those factors, and decreased the proliferation. Our data suggest that downregulation of miRNA-128 may contribute to glioma and GBM, in part, by co-ordinately upregulating ARP5 (ANGPTL6), Bmi-1 and E2F-3a, resulting in the proliferation of undifferentiated GBM cells [8].

The other commonly downregulated microRNA in GBM cell lines and tissues is microRNA-34a, which shows a significant reduction in $\mathrm{p} 53$-mutant cells compared to wild-type $p 53$ cells $[35,39]$. miR-34a interacts e.g. with MYC, CCND1, CDK6, SIRT1 and c-Met oncogenes within the transcriptome [20] and plays an important role in gliomas by inhibiting glioma tumorigenesis as a tumour suppressor with silent information regulator 1 (Sirt1) as a negative target of miR-34a in glioma cell lines. Sirt1 is an regulating apoptosis oncogene in response to oxidative stress and genomic insults [39].

EGFR and Akt activated pathways are the most common genetic alterations in glioblastoma and act together in gliomagenesis. microRNA-7, downregulated in GBM $[32,65]$, has been shown to inhibit EGFR expression, what leads to reduction in Akt phosphorylation [28]. The other targets of miRNA-7 are p21 activating kinase (PAK1) and focal adhesion kinase (FAK) microRNA-7. Therefore overexpression of microRNA-7 reduces GBM invasion and migration [3]. 
These data show the potential of miR-7 in the area of gliomas' therapeutics.

Compared to non-neoplastic brain tissue micro-

RNA-124/137 are downregulated in anaplastic astrocytomas and glioblastomas [53]. In tumour derived and neural stem cells they lead to G1 arrest and reduction in expression levels of $C D K 6$, which is a regulator of the cell cycle and known target of miRNA-124 and -137. Moreover, miRNA-137, but not miRNA-124, is activated by addition of DNA demethylating agents to glioma cell lines and that suggests methylation of $\mathrm{CpG}$ islands based on miRNA-137 promoter regulation [53].

miR-181a and miR-181b are downregulated in glioma samples and cell lines [7,52] showing 20-30\% reduction in glioblastomas. MiRNA-181b is a potential prognostic marker and helps in selection of patients who may benefit from adjuvant therapy.

microRNA-100 reduces proliferation and increases apoptosis of GBM lines by inhibiting the silencing mediator of retinoid or thyroid hormone receptor-2 (SMRT/NCOR2). Compared to normal neural cell controls it is downregulated in multiple GBM cell lines. MicroRNA-100 decreases proliferation in orthotopic GBM xenografts and extends survival [2].

\section{Peripheral blood glioblastoma biomarkers}

Monitoring of glioma development during or after completed treatment requires a reliable and quick test for biomarker detection from an easily accessible source, allowing a less extensive and more accurate disease monitoring in shorter time periods (as compared to neuroimaging) [64]. Furthermore, there could be a huge benefit from developing biomarkers for glioblastoma confirmation in order to avoid biopsy for patients with a high risk of surgeryassociated mortality or small tumours in eloquent brain areas. The specific miRNA signature in plasma samples derived from GBM patients before tumour resection would be very useful for planning the necessary degree of resection and adjuvant therapies [64]. Circulating microRNAs and exosomal microRNAs may serve as non-invasive biomarkers for various diseases, also in different cancer types $[60,64]$. Circulating miRNAs are appealing biomolecules to be considered as cancer biomarkers for several reasons including their stability, which sustain a high temperature or extreme $\mathrm{pH}$ conditions that would damage other cell components.
A significant difference in serum miRNA profile was found between untreated high-grade astrocytomas (grade III-IV) and controls in a genome-wide miRNA analysis. Seven miRNAs (miR-15b*, miR-23a, miR-133a, miR-150*, miR-197, miR-497, miR-548b-5p) were markedly decreased in grade II-IV patients, and showed high specificity (97.87\%) and sensitivity (88.00\%) for prediction of malignant astrocytomas. Furthermore, these miRNAs were also elevated in serum after operation, and some of them could be proposed as non-invasive biomarkers of malignant and benign cases, astrogliosis and other primary brain tumours $[67,68]$.

In comparison to normal controls the plasma levels of miR-21, miR-128 and miR-342-3p were shown to be significantly altered in GBM patients and miR-128 and miR-342-3p positively correlated with glioma' histopathological grade [61]. In blood of glioblastoma patients, compared with controls, miR-128 overexpression has been identified [49]. Unlike, in GBM tissue compared with normal human brain miR-128 was downregulated $[17,70]$. In the study comparing the blood samples obtained immediately after surgery versus more than 6 months after operation and after radio- and chemotherapy, miR-128 and miR-342-3p were deregulated likewise, what suggests that the detected differences are connected with the disease, not with a particular treatment [49]. Recently it has been shown that miR-454-3p in plasma of glioma patients is markedly overexpressed compared to healthy controls and are lower in LGGs than in HGGs. Also miR-29 shows high diagnostic potential, allowing to differentiate between patients of stage I-II with stage III-IV [68]. Furthermore, the miR-454-3p expression in the post-operative plasmas is markedly downregulated in comparison to the pre-operative plasmas, and a correlation of worsening prognosis of glioma was observed with increasing miR-454-3p expression [51]. Also a huge increase in miR-210 expression was found in GBM patients' serum samples compared to controls, and it was associated with the tumour grade and patient's poor outcome [68].

\section{Conclusions}

Altered miRNA biogenesis and expression in glioma plays a vital role in important signalling pathways associated with a range of tumour characteristics including gliomagenesis, invasion, and malignancy. 
The progress in our understanding of the potential involvement of miRNAs in malignant gliomas is improving rapidly, hurdles remain high before miRNAs are recognized as valid markers in HGGs. The isolation and characterization of miRNA using cellular and molecular biology techniques from the circulation of glioma patients could potentially be used for improved diagnosis, prognosis, and treatment decisions.

\section{Disclosure}

\section{Author reports no conflict of interest.}

\section{References}

1. Aldaz B, Sagardoy A, Nogueira L, Guruceaga E, Grande L, Huse JT, Aznar MA, Díez-Valle R, Tejada-Solís S, Alonso MM, FernandezLuna JL, Martinez-Climent JA, Malumbres R. Involvement of miRNAs in the differentiation of human glioblastoma multiforme stem-like cells. PLoS One 2013; 8: e77098.

2. Alrfaei BM, Vemuganti R, Kuo JS. microRNA-100 targets SMRT/ NCOR2, reduces proliferation, and improves survival in glioblastoma animal models. PLoS One 2013; 8: e80865.

3. Aoki H, Yokoyama T, Fujiwara K, Tari AM, Sawaya R, Suki D, Hess KR, Aldape KD, Kondo S, Kumar R, Kondo Y. Phosphorylated Pak1 level in the cytoplasm correlates with shorter survival time in patients with glioblastoma. Clin Cancer Res 2007; 13: 6603-6609.

4. Barbano R, Palumbo O, Pasculli B, Galasso M, Volinia S, D'Angelo V, Icolaro N, Coco M, Dimitri L, Graziano P, Copetti M, Valori VM, Maiello E, Carella M, Fazio VM, Parrella P. A miRNA signature for defining aggressive phenotype and prognosis in gliomas. PLoS One 2014; 9: e108950.

5. Bonavia R, Inda MM, Cavenee WK, Furnari FB. Heterogeneity maintenance in glioblastoma: a social network. Cancer Res 2011; 71: 4055-4060.

6. Calin GA, Ferracin M, Cimmino A, Di Leva G, Shimizu M, WojcikSE, Iorio MV, Visone R, Sever NI, Fabbri M, Iuliano R, Palumbo T, Pichiorri F, Roldo C, Garzon R, Sevignani C, Rassenti L, Alder H, Volinia S, Liu CG, Kipps TJ, Negrini M, Croce CM. A MicroRNA signature associated with prognosis and progression in chronic lymphocytic leukemia. N Engl J Med 2005; 353: 1793-1801.

7. Conti A, Aguennouz M, La Torre D, Tomasello C, Cardali S, Angileri FF, Maio F, Cama A, Germanò A, Vita G, Tomasello F. miR-21 and 221 upregulation and miR-181b downregulation in human grade II-IV astrocytic tumors. J Neurooncol 2009; 93: 325-332.

8. Cui JG, Zhao Y, Sethi P, Li YY, Mahta A, Culicchia F, Lukiw WJ. Micro-RNA-128 (miRNA-128) down-regulation in glioblastoma targets ARP5 (ANGPTL6), Bmi-1 and E2F-3a, key regulators of brain cell proliferation. J Neurooncol 2010; 98: 297-304.

9. Das P, Puri T, Jha P, Pathak P, Joshi N, Suri V, Sharma MC, Sharma BS, Mahapatra AK, Suri A, Sarkar C. A clinicopathological and molecular analysis of glioblastoma multiforme with longterm survival. J Clin Neurosci 2011; 18: 66-70.
10. Delic S, Lottmann N, Stelzl A, Liesenberg F, Wolter M, Götze S, Zapatka M, Shiio Y, Sabel MC, Felsberg J, Reifenberger G, Riemenschneider MJ. MiR-328 promotes glioma cell invasion via SFRP1-dependent Wnt-signaling activation. Neuro Oncol 2014; 16: $179-190$

11. Dews M, Fox JL, Hultine S, Sundaram P, Wang W, Liu YY, Furth E, Enders GH, El-Deiry W, Schelter JM, Cleary MA, ThomasTikhonenko A. The myc-miR-17 92 axis blunts TGF $\beta$ signaling and production of multiple TGF $\beta$-dependent antiangiogenic factors. Cancer Res 2010; 70: 8233-8246.

12. D'Urso PI, D'Urso OF, Storelli C, Mallardo M, Gianfreda CD, Montinaro A, Cimmino A, Pietro C, Marsigliante S. miR-155 is up-regulated in primary and secondary glioblastoma and promotes tumour growth by inhibiting GABA receptors. Int J Oncol 2012; 41: 228-324.

13. Gabriely G, Wurdinger T, Kesari S, Esau CC, Burchard J, Linsley PS, Krichevsky AM. MicroRNA 21 promotes glioma invasion by targeting matrix metalloproteinase regulators. Mol Cell Biol 2008; 28: 5369-5380.

14. Gal H, Pandi G, Kanner AA, Ram Z, Lithwick-Yanai G, Amariglio N, Rechavi G, Givol D. MIR-451 and Imatinib mesylate inhibit tumor growth of Glioblastoma stem cells. Biochem Biophys Res Commun 2008; 376: 86-90.

15. Garzon R, Calin GA, Croce CM. MicroRNAs in Cancer. Annu Rev Med 2009; 60: 167-179.

16. Godlewski J, Nowicki MO, Bronisz A, Nuovo G, Palatini J, De Lay M, Van Brocklyn J, Ostrowski MC, Chiocca EA, Lawler SE. MicroRNA-451 regulates LKB1/AMPK signaling and allows adaptation to metabolic stress in glioma cells. Mol Cell 2010; 37: 620-632.

17. Godlewski J, Nowicki MO, Bronisz A, Williams S, Otsuki A, Nuovo G, Raychaudhury A, Newton HB, Chiocca EA, Lawler S. Targeting of the Bmi-1 oncogene/stem cell renewal factor by microRNA-128 inhibits glioma proliferation and self-renewal. Cancer Res 2008; 68: 9125-9130.

18. González-Gómez P, Sánchez P, Mira H. MicroRNAs as regulators of neural stem cell-related pathways in glioblastoma multiforme. Mol Neurobiol 2011; 44: 235-249.

19. Grund S, Diederichs S. MicroRNA biogenesis and its impact on RNA interference in RNA technologies and their applications. In: RNA Technologies and Their Applications. Erdmann VA, Barciszewski J (eds.). Springer-Verlag, 2010; pp. 325-354.

20. Guessous F, Zhang Y, Kofman A, Catania A, Li Y, Schiff D, Purow B, Abounader R. microRNA-34a is tumor suppressive in brain tumors and glioma stem cells. Cell Cycle 2010; 9: 1031-1036.

21. Hata A, Lieberman J. Dysregulation of microRNA biogenesis and gene silencing in cancer. Sci Signal 2015; 8: re3.

22. Hegi ME, Diserens AC, Gorlia T, Hamou MF, de Tribolet N, Weller M, Kros JM, Hainfellner JA, Mason W, Mariani L, Bromberg JE, Hau P, Mirimanoff RO, Cairncross JG, Janzer RC, Stupp R. MGMT gene silencing and benefit from temozolomide in glioblastoma. N Engl J Med 2005; 352: 997-1003.

23. Hermeking H. The miR-34 family in cancer and apoptosis. Cell Death Differ 2010; 17: 193-199.

24. Holdhoff M, Grossman SA. Controversies in the adjuvant therapy of high-grade gliomas. Oncologist 2011; 16: 351-358.

25. Homma T, Fukushima T, Vaccarella S, Yonekawa Y, Di Patre PL, Franceschi S, Ohgaki H. Correlation among pathology, geno- 
type, and patient outcomes in glioblastoma. J Neuropathol Exp Neurol 2006; 65: 846-854.

26. International Agency for Research on Cancer (IARC) GLOBOCAN 2012. Estimated Incidence, Mortality and 5-Year Prevalence: Both Sexes; accessed on 5 February 2016, globocan.iarc.fr.

27. Jansen M, Yip S, Louis DN. Molecular pathology in adult gliomas: diagnostic, prognostic, and predictive markers. Lancet Neurol 2010; 9: 717-726.

28. Kefas B, Godlewski J, Comeau L, Li Y, Abounader R, Hawkinson M, Lee J, Fine H, Chiocca EA, Lawler S, Purow B. microRNA-7 inhibits the epidermal growth factor receptor and the Akt pathway and is down-regulated in glioblastoma. Cancer Res 2008; 68: 3566-3572.

29. Kim TM, Huang W, Park R, Park PJ, Johnson MD. A developmental taxonomy of glioblastoma defined and maintained by microRNAs. Cancer Res 2011; 71: 3387-3399.

30. Koo S, Martin GS, Schulz KJ, Ronck M, Toussaint LG. Serial selection for invasiveness increases expression of miR-143/miR-145 in glioblastoma cell lines. BMC Cancer 2012; 12: 143.

31. Lages E, Guttin A, El Atifi M, Ramus C, Ipas H, Dupré I, Rolland D, Salon C, Godfraind C, deFraipont F, Dhobb M, Pelletier L, Wion D, Gay E, Berger F, Issartel JP. MicroRNA and target protein patterns reveal physiopathological features of glioma subtypes. PLoS One 2011; 6: e20600.

32. Leber MF, Bossow S, Leonard VH, Zaoui K, Grossardt C, Frenzke M, Miest T, Sawall S, Cattaneo R, von Kalle C, Ungerechts G. MicroRNA-sensitive oncolytic measles viruses for cancer-specific vector tropism. Mol Ther 2011; 19: 1097-1106.

33. Lee SJ, Kim SJ, Seo HH, Shin SP, Kim D, Park CS, Kim KT, Kim YH, Jeong JS, Kim IH. Over-expression of miR-145 enhances the effectiveness of HSVtk gene therapy for malignant glioma. Cancer Lett 2012; 320: 72-80

34. Li D, Chen P, Li XY, Zhang LY, Xiong W, Zhou M, Xiao L, Zeng F, Li XL, Wu MH, Li GY. Grade-specific expression profiles of miRNAs/ mRNAs and docking study in human grade I-III astrocytomas. OMICS 2011; 15: 673-682.

35. Li Y, Guessous F, Zhang Y, Dipierro C, Kefas B, Johnson E, Marcinkiewicz L, Jiang J, Yang Y, Schmittgen TD, Lopes B, Schiff D, Purow B, Abounader R. MicroRNA-34a inhibits glioblastoma growth by targeting multiple oncogenes. Cancer Res 2009; 69: 7569-7576.

36. Lin S, Gregory RI. MicroRNA biogenesis pathways in cancer. Nat Rev Cancer 2015; 15: 321-333.

37. Louis DN, Ohgaki H, Wiestler OD, Cavenee WK (eds.). World Health Organization Classification of Tumours of the Central Nervous System. IARC, Lyon 2007.

38. Lu J, Getz G, Miska EA, Alvarez-Saavedra E, Lamb J, Peck D, Sweet-Cordero A, Ebert BL, Mak RH, Ferrando AA, Downing JR, Jacks T, Horvitz HR, Golub TR. MicroRNA expression profiles classify human cancers. Nature 2005; 435: 834-838.

39. Luan S, Sun L, Huang F. MicroRNA-34a: a novel tumor suppressor in p53-mutant glioma cell line U251. Arch Med Res 2010; 41: 67-74.

40. Lukiw WJ, Cui JG, Li YY, Culicchia F. Up-regulation of microRNA-221 (miRNA-221; chr Xp11.3) and caspase-3 accompanies down-regulation of the survivin-1 homolog BIRC1 (NAIP) in glioblastoma multiforme (GBM). J Neurooncol 2009; 91: 27-32.
41. Malzkorn B, Wolter M, Liesenberg F, Grzendowski M, Stühler K, Meyer HE, Reifenberger G. Identification and functional characterization of microRNAs involved in the malignant progression of gliomas. Brain Pathol 2010; 20: 539-550.

42. Medina R, Zaidi SK, Liu CG, Stein JL, van Wijnen AJ, Croce CM, Stein GS. MicroRNAs 221 and 222 bypass quiescence and compromise cell survival. Cancer Res 2008; 68: 2773-2780.

43. Morokoff A, Ng W, Gogos A, Kaye AH. Molecular subtypes, stem cells and heterogeneity: Implications for personalised therapy in glioma. J Clin Neurosci 2015; 22: 1219-1226.

44. Nan Y, Han L, Zhang A, Wang G, Jia Z, Yang Y, Yue X, Pu P, Zhong Y, Kang C. MiRNA-451 plays a role as tumor suppressor in human glioma cells. Brain Res 2010; 1359: 14-21.

45. Papagiannakopoulos T, Shapiro A, Kosik KS. MicroRNA-21 targets a network of key tumor-suppressive pathways in glioblastoma cells. Cancer Res 2008; 68: 8164-8172.

46. Phillips HS, Kharbanda S, Chen R, Forrest WF, Soriano RH, Wu TD, Misra A, Nigro JM, Colman H, Soroceanu L, Williams PM, Modrusan Z, Feuerstein BG, Aldape K. Molecular subclasses of highgrade glioma predict prognosis, delineate a pattern of disease progression, and resemble stages in neurogenesis. Cancer Cell 2006; 9: 157-173.

47. Piwecka M, Rolle K, Belter A, Barciszewska AM, Żywicki M, Michalak M, Nowak S, Naskręt-Barciszewska MZ, Barciszewski J. Comprehensive analysis of microRNA expression profile in malignant glioma tissues. Mol Oncol 2015; 9: 1324-1340.

48. Rivera AL, Pelloski CE, Gilbert MR, Colman H, De La Cruz C, Sulman EP, Bekele BN, Aldape KD. MGMT promoter methylation is predictive of response to radio-therapy and prognostic in the absence of adjuvant alkylating chemotherapy for glioblastoma. Neuro Oncol 2010; 12: 116-121.

49. Roth P, Wischhusen J, Happold C, Chandran PA, Hofer S, Eisele G, Weller M, Keller A. A specific miRNA signature in the peripheral blood of glioblastoma patients. J Neurochem 2011; 118: 449457.

50. Sasayama T, Nishihara M, Kondoh T, Hosoda K, Kohmura E. MicroRNA-10b is overexpressed in malignant glioma and associated with tumor invasive factors, UPAR and RhoC. Int J Cancer 2009; 125: 1407-1413.

51. Shao N, Wang L, Xue L, Wang R, Lan Q. Plasma miR-454-3p as a potential prognostic indicator in human glioma. Neurol Sci 2015; 36: 309-313.

52. Shi L, Cheng Z, Zhang J, Li R, Zhao P, Fu Z, You Y. hsa-mir-181a and hsa-mir-181b function as tumor suppressors in human glioma cells. Brain Res 2008; 1236: 185-193.

53. Silber J, Lim DA, Petritsch C, Persson Al, Maunakea AK, Yu M, Vandenberg SR, Ginzinger DG, James CD, Costello JF, Bergers G, Weiss WA, Alvarez-Buylla A, Hodgson JG. miR-124 and miR-137 inhibit proliferation of glioblastoma multiforme cells and induce differentiation of brain tumor stem cells. BMC Med 2008; 6: 14.

54. Stefani G, Slack FJ. Small non-coding RNAs in animal development. Nat Rev Mol Cell Biol 2008; 9: 219-230.

55. Stein RA. MicroRNAs rise from trash to treasure. Genetic Engineering \& Biotechnology News (GEN) 2016; 36.

56. Stupp R, Mason WP, van den Bent MJ, Weller M, Fisher B, Taphoorn MJ, Belanger K, Brandes AA, Marosi C, Bogdahn U, Curschmann J, Janzer RC, Ludwin SK, Gorlia T, Allgeier A, Lacombe D, 
Cairncross JG, Eisenhauer E, Mirimanoff RO; EORTC Brain Tumor and Radiotherapy Groups; National Cancer Institute of Canada Clinical Trials Group. Radiotherapy plus concomitant and adjuvant temozolomide for glioblastoma. N Engl J Med 2005; 352 987-996.

57. van den Bent MJ, Carpentier AF, Brandes AA, Sanson M, Taphoorn MJ, Bernsen HJ, Frenay M, Tijssen CC, Grisold W, Sipos L, Haaxma-Reiche H, Kros JM, van Kouwenhoven MC, Vecht CJ, Allgeier A, Lacombe D, Gorlia T. Adjuvant procarbazine, lomustine, and vincristine improves progression-free survival but not overall survival in newly diagnosed anaplastic oligodendrogliomas and oligoastrocytomas: a randomized EORTC phase III trial. J Clin Oncol 2006; 24: 2715-2722.

58. van den Bent MJ, Dubbink HJ, Marie Y, Brandes AA, Taphoorn MJ, Wesseling P, Frenay M, Tijssen CC, Lacombe D, Idbaih A, van Marion R, Kros JM, Dinjens WN, Gorlia T, Sanson M. IDH1 and IDH2 mutations are prognostic but not predictive for outcome in anaplastic oligodendroglial tumors: a report of the EORTC Brain Tumor Group. Clin Cancer Res 2010; 16: 1597-1604.

59. Visani M, de Biase D, Marucci G, Cerasoli S, Nigrisoli E, Bacchi Reggiani ML, Albani F, Baruzzi A, Pession A; PERNO study group. Expression of 19 microRNAs in glioblastoma and comparison with other brain neoplasia of grades I-III. Mol Oncol 2014; 8: 417-430.

60. Wang J, Chen J, Sen S. MicroRNA as Biomarkers and Diagnostics. J Cell Physiol 2016; 231: 25-30.

61. Wang Q, Li P, Li A, Jiang W, Wang H, Wang J, Xie K. Plasma specific miRNAs as predictive biomarkers for diagnosis and prognosis of gliomas. J Exp Clin Cancer Res 2012; 31: 97.

62. Weller M, Felsberg J, Hartmann C, Berger H, Steinbach JP, Schramm J, Westphal M, Schackert G, Simon M, Tonn JC, Heese O, Krex D, Nikkhah G, Pietsch T, Wiestler O, Reifenberger G, von Deimling A, Loeffler M. Molecular predictors of progression-free and overall survival in patients with newly diagnosed glioblastoma: a prospective translational study of the German Glioma Network. J Clin Oncol 2009; 27: 5743-5750.

63. Wen PY, Kesari S. Malignant gliomas in adults. N Engl J Med 2008; 359: 492-507.

64. Westphal M, Lamszus K. Circulating biomarkers for gliomas. Nat Rev Neurol 2015; 11: 556-566.

65. Wuchty S, Arjona D, Li A, Kotliarov Y, Walling J, Ahn S, Zhang A, Maric D, Anolik R, Zenklusen JC, Fine HA. Prediction of Associations between microRNAs and Gene Expression in Glioma Biology. PLoS One 2011; 6: e14681.

66. Yanaihara N, Caplen N, Bowman E, Seike M, Kumamoto K, Yi M, Stephens RM, Okamoto A, Yokota J, Tanaka T, Calin GA, Liu CG, Croce CM, Harris CC. Unique microRNA molecular profiles in lung cancer diagnosis and prognosis. Cancer Cell 2006; 9: 189-198.

67. Yang C, Wang C, Chen X, Chen S, Zhang Y, Zhi F, Wang J, Li L, Zhou X, Li N, Pan H, Zhang J, Zen K, Zhang CY, Zhang C. Identification of seven serum microRNAs from a genome-wide serum microRNA expression profile as potential noninvasive biomarkers for malignant astrocytomas. Int I Cancer 2013; 132: 116-127.

68. YU X, Li Z. Serum microRNAs as potential noninvasive biomarkers for glioma. Tumour Biol 2016; 37: 1407-1410.

69. Zhang C, Zhang J, Hao J, Shi Z, Wang Y, Han L, Yu S, You Y, Jiang T, Wang J, Liu M, Pu P, Kang C. High level of miR-221/222 confers increased cell invasion and poor prognosis in gliomas. J Transl Med 2012; 10: 119

70. Zhang Y, Chao T, Li R, Liu W, Chen Y, Yan X, Gong Y, Yin B, Liu W, Qiang B, Zhao J, Yuan J, Peng X. MicroRNA-128 inhibits glioma cells proliferation by targeting transcription factor E2F3a. J Mol Med (Berl) 2009; 87: 43-51. 